\title{
EFEITO DE ÓLEOS ESSENCIAIS COMO PROMOTORES DE CRESCIMENTO EM LEITÕES RECÉM-DESMAMADOS\#
}

\author{
EFECTS OF ESSENTIAL OILS AS GROWTH PROMOTERS ON PERFORMANCE OF \\ WEANED PIGS
}

\author{
Branco, P.A.C. ${ }^{*}$, Soares, R. ${ }^{2}$, Vieites, F. ${ }^{3}$, Cabral, N. ${ }^{2}$ e Tavares, E. ${ }^{2}$ \\ ${ }^{1}$ Universidade de Cuiabá. Campus Sinop. Mato Grosso. Brasil. *patriciaacbvale@hotmail.com \\ ${ }^{2}$ LZNA/CCTA/Universidade Estadual do Norte Fluminense. Rio de Janeiro. Brasil. \\ ${ }^{3}$ Universidade Federal de Mato Grosso (UFMT). Campus Rondonópolis. Mato Grosso. Brasil.
}

\section{PaLAVRAS ChaVE ADICIONAIS}

Aditivos. Antimicrobiano. Pró-nutrientes.

\section{RESUMO}

Objetivou-se avaliar o efeito de antibiótico e óleos essenciais sobre a digestibilidade das rações e desempenho de leitões recém-desmamados. Foram realizados dois experimentos, utilizando o delineamento em blocos casualizados, com cinco tratamentos (T1: controle - ração basal; T2: basal + antibiótico (0,2\%); T3, T4 e T5: basal + 0,02; 0,04 e $0,06 \%$ de Tecnaroma Herbal (TH), respectivamente), quatro repetições e três animais por unidade experimental (desempenho) e um animal por unidade experimental (digestibilidade). O desempenho foi determinado com 60 leitões e a digestibilidade utilizando 20 leitões. O TH é um produto comercial constituído por sete tipos de óleos essenciais (aniz, aniz estrelado, tomilho, orégano, alho, eucalipto (globulus e citriodora) e ginepro. O maior nível de inclusão do TH (T5) foi o que proporcionou os melhores resultados de desempenho. Os animais do tratamento controle foram os que apresentaram os piores resultados. Os tratamentos contendo os dois maiores níveis de inclusão dos óleos essenciais determinaram maior digestibilidade dos contituintes da ração. Os resultados encontrados nesta pesquisa sugerem que o produto $\mathrm{TH}$ pode, com grandes chances de sucesso, ser utilizado como aditivo alternativo aos agentes antimicrobianos como promotores do crescimento de leitões.

\#Parte da tese de doutorado da primeira autora.

\section{AdDitionAL KEYWORDS}

Additives. Antimicrobian. Pro-nutrients.

\section{SUMMARY}

Two trials were conducted to evaluate the effects of antibiotic and essential oils on diets digestibility and performance in weaned pigs. Sixty weaned pigs (in performance trial) and twelve piglets (in digestibility trial), in a randomized block design, were used to compare five treatments: T1: control - basal diet; T2: basal diet + antibiotic $(0,2 \%) ;$ T3, T4 e T5: basal diet + 0,02; 0,04 e $0,06 \%$ essential oil (TH), respectively, with four replications and three pigs per experimental unit (performance) and one pig per experimental unit (digestibility). The Tecnaroma Herbal (TH) is a commercial product consisted of mixture of seven types of essential oils (anise, star anise, thyme, oregano, garlic, eucalyptus and ginepro). The highest level of TH (T5) improved the performance of animals. Two highest levels of essentials oils increased dietary digestibility compared to control and antibiotic treatments. The results of this study suggest that the product TH can be used, with great chances of success, as an additive alternate to antimicrobial agents as growth promoters for piglets.

\section{INTRODUÇÃO}

No sistema confinado de produção de suínos, o período mais crítico para criação dos animais vai do nascimento ao final da creche. A redução do período lactacional, associado à imaturidade digestiva dos 
BRANCO, SOARES, VIEITES, CABRALETAVARES

leitões, determinou que técnicos e produtores utilizas sem mais os antibióticos e quimioterápicos (Menten, 2001).

A demanda de alimentos para atender às necessidades da população mundial requer maior produção intensiva de proteína de origem animal respeitando cada vez mais o meio ambiente e a segurança alimentar.

$\mathrm{O}$ uso de antibióticos como promotores de crescimento é praticado desde os anos 50 (Menten, 2002). Porém, apesar da comprovada capacidade de melhorar o desempenho de suínos, o uso de antimicrobianos como promotores do crescimento vem sendo progressivamente restringido, pela possibilidade de desenvolvimento da resistência bacteriana cruzada em humanos e à emergente exigência dos importadores por produtos livres de resíduos de antibióticos (Silva, 2000). Essas regulamentações têm forçado a procura por alternativas que garantam o máximo crescimento dos animais sem afetar a qualidade do produto (Miltenberg, 2000).

A utilização de óleos essenciais, extratos vegetais e plantas medicinais para humanos foi muito difundida no Egito Antigo, na China, na Índia e na Grécia (Kamel, 2000). Os principais efeitos pesquisados em experimentos in vitro incluem o efeito antimicrobiano e antioxidante dos extratos herbais. Os efeitos exercidos pelas plantas podem ser explicados pela presença e constituição de seu(s) princípio(s) ativo(s). Na formulação de rações, recomenda-se a utilização de uma combinação de diferentes extratos herbais, reforçados com seus princípios ativos, para atingir resultados técnicos satisfatórios (Brugalli, 2003). No entanto, ainda não foi esclarecido se uma ação particular, pode estar associada a uma molécula específica e/ou alguma substância ativa presente na planta, que pode ter múltiplas funções (Brugalli, 2003).

Entre os possíveis mecanismos de ação dos óleos essenciais no organismo animal, pode-se citar estimulação da digestão, alterações na microbiota intestinal, aumen- to na digestibilidade e absorção de nutrientes e efeitos antimicrobiano e imunomodulador (Mellor, 2000). Apesar da comprovada ação in vitro de diversos extratos herbais e seus óleos essenciais, existem poucas informações sobre a efetividade em suínos.

O efeito antimicrobiano de um óleo essencial está principalmente associado: à alteração da permeabilidade e integridade da membrana celular bacteriana; à relação entre a estrutura química dos compostos ativos presentes e seu efeito antimicrobiano, sendo estes compostos com características hidrofílicas e lipofílicas (Farag et al., 1989); e ao tipo de microrganismo testado, principalmente às características de sua membrana celular (Kalemba e Kunicka, 2003).

De acordo com Kamel (2000), em alguns casos, os óleos essenciais apresentam atividade antimicrobiana mais pronunciada do que alguns antibióticos: o eugenol, por exemplo, apresentou maior efeito bactericida contra a E. coli, Enterobacter sakazakii e Klebsiela pneumoniae do que antibióticos e quimioterápicos como ampicilina, eritromicina e sulfametazol.

Segundo Mellor (2000), os óleos essenciais podem estimular a produção de saliva e dos sucos gástrico e pancreático, influenciando positivamente a secreção de enzimas pancreáticas, da sacarase e da maltase, melhorando a digestibilidade dos nutrientes. Uma adequada digestão dos alimentos refletirá positivamente na microbiota intestinal, absorção de nutrientes, taxa de passagem do alimento e, consequentemente, na saúde e desempenho do animal (Jones, 2001).

Objetivou-se com este estudo avaliar o efeito de níveis crescentes da combinação de óleos essenciais e de um antibiótico sobre o desempenho de leitões recémdesmamados e a digestibilidade dos nutrientes das rações experimentais.

\section{MATERIALE MÉTODOS}

Para avaliar o desempenho de leitões 


\section{ÓLEOS ESSENCIAIS E DESEMPENHO DE LEITÕES RECÉM-DESMAMADOS}

alimentados com rações contendo o produto Tecnaroma ZTA Herbal Mix ${ }^{\circledR}(\mathrm{TH})$ como um aditivo sensorial natural composto por sete tipos de óleos essenciais (aniz, aniz estrelado, tomilho, orégano, alho, eucalipto (globulus e citriodora) e ginepro), um experimento foi conduzido no Setor de Suinocultura da Unidade de Apoio à Pesquisa em Zootecnia do Laboratório de Zootecnia e Nutrição Animal do CCTA-UENF. Foram utilizados 60 leitões mestiços (machos castrados e fêmeas) com média de 21 dias de idade e peso inicial de $8,0 \mathrm{~kg} \pm 1,2 \mathrm{~kg}$, distribuídos em um delineamento em blocos ao acaso, com cinco tratamentos, quatro repetições e três animais por unidade experimental. Na formação dos blocos, foi considerado o peso inicial dos animais. Os leitões foram alojados em baias de piso de cimento, equipadas com comedouros de concreto e bebedouro tipo chupeta. Água e rações foram fornecidas à vontade durante todo o período experimental.

Para avaliar o efeito do antibiótico e dos óleos essenciais sobre a digestibilidade das rações experimentais, 20 suínos machos castrados mestiços, com 63 dias de idade e peso vivo médio $22,0 \mathrm{~kg} \pm 5,0 \mathrm{~kg}$ foram alojados em gaiolas de metabolismo, segundo técnica descrita por Fialho et al. (1982), com algumas modificações.

Os tratamentos consistiram de: T1: controle - ração basal; T2- ração basal + 0,2\% antibiótico, T3- ração basal $+0,02 \% \mathrm{TH}$ (TH1); T4- ração basal + 0,04\% TH (TH2) e T5- ração basal + 0,06\% TH (TH3). O TH é um aditivo sensorial, à base de óleos essenciais aromáticos e extratos de plantas e ervas aromáticas, composto por timo ou tomilho, orégano, alho, aniz, aniz estrelado, ginepro e eucalipto, enquanto o antibiótico utilizado foi o Trissulfim ${ }^{\circledR}$, produto à base de bromexina, sulfonamidas e trimetoprima.

As rações experimentais foram formuladas à base de milho e farelo de soja e suplementadas com vitaminas, minerais e aminoácidos para atender às exigências nutricionais dos suínos na fase inicial, de acordo com Rostagno (2005). Foram utilizadas duas rações basais durante o ensaio de desempenho: pré-inicial (1-21 dias de experimentação) e inicial (22-42 dias de experimentação). No ensaio de digestibilidade utilizou-se apenas a ração inicial. As composições percentuais das rações basais encontram-se na tabela $\mathbf{I}$.

No ensaio de desempenho, as variáveis avaliadas foram o consumo de ração diário,

Tabela I. Composições centesimal e nutricional das rações basais. (Ingredient and calculated compositions of the basal diets).

\begin{tabular}{lcc}
\hline Ingredientes (kg) & $\begin{array}{c}\text { Pré-inicial } \\
(1-21 \text { dias) }\end{array}$ & $\begin{array}{c}\text { Inicial } \\
(22-42 \text { dias })\end{array}$ \\
\hline Milho comum & 50,40 & 64,45 \\
Farelo de soja & 33,30 & 30,00 \\
Leite pó & 5,00 & - \\
Açúcar cristal & 5,00 & 1,00 \\
Óleo de soja & 2,30 & - \\
Fosf. bicálcico & 1,40 & 1,80 \\
Calcário & 0,70 & 0,85 \\
Sal & 0,25 & 0,25 \\
S. vit. e min. & 0,50 & 0,50 \\
L-Lisina HCl & 0,30 & 0,30 \\
DL-Metionina & 0,15 & 0,15 \\
L-Treonina & 0,10 & 0,10 \\
Inerte (areia) & 0,60 & 0,60 \\
TOTAL & 100,00 & 100,00 \\
Nível nutricional calculado & & \\
ED (kcal/kg) & 3400 & 3300 \\
PD (\%) & 20,00 & 19,5 \\
Ca (\%) & 0,85 & 0,85 \\
P total (\%) & 0,70 & 0,70 \\
\hline
\end{tabular}

${ }^{1}$ Nineis de garantia por $\mathrm{kg}$ do produto: Vit. A: 3500000 UI; Vit. D3: 500000 UI; Vit. E: 5000 mg; Vit. K: 1000 mg; Vit. B1: 400 mg; Vit. B2: 1600 mg; Vit. B6: $500 \mathrm{mg}$; Vit B12: $11000 \mathrm{mcg}$; Ácido fólico: $350 \mathrm{mg}$; Biotina: $10 \mathrm{mg}$; Niacina: $14000 \mathrm{mg}$; Pantotenato de cálcio: $6000 \mathrm{mg}$; Co: $9000 \mathrm{mg}$; Fe: 48000 $\mathrm{mg}$; I: $125 \mathrm{mg}$; Mn: $25000 \mathrm{mg}$; Se: $75 \mathrm{mg}$; Antioxidante: $2000 \mathrm{mg}$; Veículo q.s.p.: $1000 \mathrm{~g}$. ${ }^{2}$ Nos dois experimentos, os microingredientes testados foram adicionados às rações basais em substituição parcial e/ou total ao inerte. 
ganho de peso diário e conversão alimentar. Estas variáveis foram calculadas por meio da pesagem dos animais e quantificações das rações, feitas semanalmente.

Para determinação da digestibilidade, 20 leitões do primeiro experimento, receberam as respectivas rações experimentais. Utilizou-se o método da coleta total de fezes. A coleta de fezes foi realizada durante cinco dias (manhã e tarde), com início no $7^{\circ}$ dia de experimentação.

Durante o período experimental, em ambos os ensaios, os animais receberam água e ração à vontade.

Os coeficientes de digestibilidade da energia bruta, proteína bruta e matéria seca das rações experimentais foram obtidos utilizando-se uma equação segundo Andriguetto (1986).

A análise estatística dos parâmetros estudados foi realizada de acordo com o programa SAEG versão 7.1 (sistema de análises estatísticas e genéticas), desenvolvido pela Universidade Federal de Viçosa, utilizando-se a Análise de Variância, sendo as médias dos tratamentos comparadas pelo teste de Student Newman Keuls (SNK).

As características de desempenho foram submetidas à análise de regressão, sendo a resposta das variáveis analisadas avaliada em função da decomposição da soma de quadrados referentes aos níveis do produto testado (Tecnaroma ZTA Herbal Mix ${ }^{\circledR}$ ) em seus componentes (linear, quadrático e cúbico).

\section{RESULTADOSEDISCUSSÃO}

As médias das variáveis de desempenho são apresentadas nas tabelas II, III e IV, respectivamente para os períodos de 1 a 21 , 22 a 42 e 1 a 42 dias de experimentação.

As equações de regressão das variáveis de desempenho, em função dos níveis de inclusão do produto $\mathrm{TH}$, são apresentadas na tabela $\mathbf{V}$.

No período experimental de 1 a 21 dias não ocorreram diferenças significativas
Tabela II. Consumo de ração médio diário (CRMD, $\mathrm{kg} /$ dia), ganho de peso médio diário (GPMD, kg/dia) e conversão alimentar (CA) de leitões de 1-21 dias de experimentação. (Average daily feed intake (CRMD, $\mathrm{kg} /$ day), average daily weight gain (GPMD, kg/day) and feed conversion $(F / G)$ of weaned pigs from 1 to 21 days of experiment).

\begin{tabular}{lccc}
\hline Tratamentos & CRMD & GPMD & CA \\
\hline Controle & 0,403 & 0,239 & 1,71 \\
Antibiótico & 0,397 & 0,245 & 1,65 \\
TH1 & 0,393 & 0,251 & 1,57 \\
TH2 & 0,392 & 0,292 & 1,46 \\
TH3 & 0,384 & 0,239 & 1,46 \\
Média & 0,394 & 0,258 & 1,55 \\
CV $(\%)$ & 5,61 & 11,94 & 14,22 \\
\hline
\end{tabular}

TH: Tecnaroma herbal.

entre os tratamentos $(p>0,05)$ para nenhuma das variáveis avaliadas, isto é, o aumento dos níveis do produto não influenciou, positiva ou negativamente, o desempenho dos animais.

Tabela III. Consumo de ração médio diário individual (CRMD, kg/dia), ganho de peso médio diário individual (GPMD, $\mathrm{kg} /$ dia) e conversão alimentar (CA) de leitões de 2242 dias de experimentação. (Average daily feed intake (CRMD, kg/day), average daily weight gain (GPMD, kg/day) and feed conversion (F/G) of weaned pigs from 22 to 42 days of experiment).

\begin{tabular}{lccc}
\hline Tratamentos & CRMD & GPMD & CA \\
\hline Controle & $1,019^{\mathrm{b}}$ & $0,652^{\mathrm{b}}$ & $1,56^{\mathrm{a}}$ \\
Antibiótico & $1,030^{\mathrm{b}}$ & $0,691^{\mathrm{ab}}$ & $1,49^{\mathrm{a}}$ \\
TH1 & $1,167^{\mathrm{ab}}$ & $0,755^{\mathrm{ab}}$ & $1,55^{\mathrm{a}}$ \\
TH2 & $1,234^{\mathrm{a}}$ & $0,877^{\mathrm{a}}$ & $1,42^{\mathrm{ab}}$ \\
TH3 & $1,158^{\mathrm{ab}}$ & $0,869^{\mathrm{a}}$ & $1,34^{\mathrm{b}}$ \\
Média & 1,121 & 0,769 & 1,47 \\
CV $(\%)$ & 7,84 & 12,77 & 5,49 \\
\hline
\end{tabular}

TH: Tecnaroma herbal; abMédias seguidas de letras diferentes na mesma coluna, dentro de cada variável, diferem entre si pelo Teste SNK $(p<0,05)$. 


\section{ÓLEOS ESSENCIAIS E DESEMPENHO DE LEITÕES RECÉM-DESMAMADOS}

Tabela IV. Consumo de ração médio diário (CRMD kg/dia), ganho de peso médio diário ( $G P M D$, kg/dia) e conversão alimentar (CA) de leitões de 1-42 dias de experimentação. (Average daily feed intake (CRMD, kg/day), average daily weight gain (GPMD, $\mathrm{kg} / \mathrm{day}$ ) and feed conversion $(F / G)$ of weaned pigs from 1 to 42 days of experiment).

\begin{tabular}{lccc}
\hline Tratamentos & CRMD & GPMD & CA \\
\hline Controle & $0,711^{\mathrm{b}}$ & $0,446^{\mathrm{b}}$ & $1,60^{\mathrm{a}}$ \\
Antibiótico & $0,713^{\mathrm{b}}$ & $0,468^{\mathrm{b}}$ & $1,53^{\mathrm{a}}$ \\
TH & $0,780^{\mathrm{ab}}$ & $0,503^{\mathrm{ab}}$ & $1,56^{\mathrm{a}}$ \\
TH2 & $0,813^{\mathrm{a}}$ & $0,584^{\mathrm{a}}$ & $1,45^{\mathrm{a}}$ \\
TH3 & $0,771^{\mathrm{ab}}$ & $0,567^{\mathrm{a}}$ & $1,37^{\mathrm{b}}$ \\
Média & 0,758 & 0,514 & 1,49 \\
CV (\%) & 5,53 & 12,26 & 7,40 \\
\hline
\end{tabular}

TH: Tecnaroma herbal; abMédias seguidas de letras diferentes na mesma coluna, dentro de cada variável, diferem entre si pelo Teste $\operatorname{SNK}(p<0,05)$.

Durante os períodos de 22 a 42 e 1 a 42 dias de experimentação, os animais que receberam o tratamento $\mathrm{TH} 2$ apresentaram maiores consumos $(\mathrm{p}<0,05)$, sendo observado um efeito quadrático negativo dos níveis do produto para esta característica. Com relação ao GPMD, os animais que receberam os tratamentos TH2 e TH3 apresentaram os maiores valores $(\mathrm{p}<0,05)$ Para esta variável, foi observado um efeito linear positivo dos níveis do produto. Para a CA, o melhor valor $(\mathrm{p}<0,05)$ foi observado nos animais que receberam o tratamento $\mathrm{TH} 3$, com um efeito linear negativo dos níveis do produto testado. Considerando os resultados de ganho de peso, a redução no consumo de ração em detrimento do aumento do nível do produto não foi suficiente para deprimir o desempenho dos animais que receberam o tratamento $\mathrm{TH} 3, \mathrm{o}$ que pode ser justificado pela melhor conversão alimentar apresentada por estes animais. Essa melhor CA pode ter sido resultado de uma melhor absorção dos nutrientes, aliada ao menor gasto de energia e proteína para a manutenção da integridade do trato gastrintestinal (Utiyama et al., 2006). Os animais que receberam tratamento sem aditivo (controle) apresentaram pior desempenho.

O melhor desempenho dos animais que receberam óleos essenciais na dieta $(\mathrm{TH} 2$ e TH3) pode ser devido ao efeito positivo na atividade enzimática, podendo estimular a produção de saliva e de suco gástrico e pancreático, influenciando positivamente a secreção de enzimas digestivas, melhorando a digestibilidade dos nutrientes (Mellor, 2000).

Tabela $\boldsymbol{V}$. Equações de regressão das variáveis de desempenho, em função dos níveis de inclusão do produto TH, avaliadas em cada período de experimentação. (Regression equations of the variables of performance, depending on the levels of inclusion of TH product, valued at each period of experimentation).

\begin{tabular}{cclr}
\hline Período de experimentação & Variáveis & Equação de regressão & $R^{2}$ \\
\hline \multirow{2}{*}{ 1 a 21 dias } & - & ns & - \\
& CRMD & $Y=1,0164+10,8185^{* *} X-140,166^{*} X^{2}$ & 0,46 \\
& GPMD 42 dias & $Y=0,6726+3,8503^{* *} X$ & 0,44 \\
& CA & $Y=1,589-4,0102^{* *} X$ & 0,60 \\
& & & \\
1 a 42 dias & CRMD & $Y=0,6144+11,1607^{* *} X-141,208^{*} X^{2}$ & 0,45 \\
& GPMD & $Y=0,4288+3,2475^{\star *} X$ & 0,51 \\
& CA & $Y=1,546-3,5778^{* *} X$ & 0,49 \\
\hline
\end{tabular}

TH: Tecnaroma herbal; ns= não significativo; ${ }^{*} \mathrm{p} \leq 0,05 ;{ }^{* *} \mathrm{p} \leq 0,01$. 
BRANCO, SOARES, VIEITES, CABRALETAVARES

Há também o efeito antimicrobiano, considerado o principal modo de ação dos óleos essenciais. O efeito antimicrobiano está relacionado, principalmente, à alteração da permeabilidade e integridade da membrana celular bacteriana, o que permite que atuem como agentes bactericidas ou bacteriostáticos, causando efeitos interativos com a fisiologia do animal, como a economia de nutrientes, o efeito protetor contra a produção de toxinas no trato gastrintestinal, o efeito no controle de doenças subclínicas e o efeito metabólico (Menten, 2002). Além desses efeitos, pode-se citar também o fato de que a adição de óleos essenciais e extratos vegetais, como os obtidos do orégano, proporcionam o crescimento de microrganismos benéficos, favorecendo o desempenho animal (Lima et al., 1999; Zuanon et al., 1998).

Os dados encontrados neste experimento diferem, dos encontrados por Utiyama et al. (2006), Oetting et al. (2006) e Costa et al. (2007), os quais, trabalhando com leitões jovens, conduziram pesquisas para testarem diferentes tipos de extratos vegetais e observaram, de modo geral, melhor desempenho nos animais que receberam rações experimentais com antibiótico, em comparação àqueles animais que receberam ração contendo diferentes tipos e níveis de extratos vegetais.

Algumas hipóteses podem ser utilizadas para explicar a diferença entre os dados obtidos no presente experimento em comparação aos supracitados. Uma delas seria a de que para os extratos vegetais apresentarem os dois efeitos mais comumente observados, isto é, o antimicrobiano e o de estimulação do sistema enzimático, e que estes possam ser observados in vivo, os níveis de inclusão na dieta devem ser elevados ou suplementados em combinações de diferentes extratos, cujos componentes se completam e apresentam efeito sinérgico.

Pesquisas já demonstraram a existência de um efeito sinérgico entre componentes primários e secundários das plantas (Kamel, 2000), sendo que os componentes secundários (na maior parte, os princípios ativos em óleos essenciais) atuam como potencializadores dos componentes primários.

A tabela VI mostra as médias dos coeficientes de digestibilidade aparente da mataria seca (CDMS), da proteína bruta (CDPB) e da energia bruta(CDEB) em função dos tratamentos.

A inclusão de níveis crescentes de óleos essenciais às rações promoveu o aumento $(\mathrm{p}<0,05)$ da digestibilidade da matéria seca em relação ao tratamento controle, sendo este efeito mais expressivo no tratamento com maior nível de inclusão dos óleos essenciais. Estes resultados estão de acordo com os encontrados por Oetting et al. (2006) que, trabalhando com leitões desmamados, observaram um aumento no coeficiente de digestibilidade da matéria seca, em relação ao tratamento controle, quando da inclusão de níveis crescentes de extratos vegetais. Hernández et al. (2004) também encontraram resposta semelhante às obtidas no presente

Tabela VI. Médias dos coeficientes de digestibilidade aparente (\%) da matéria seca (MS), da proteína bruta (PB) e da energia bruta (EB) em função dos tratamentos. (Average percentage apparent digestibility of dry matter (MS), crude protein (PB) and gross energy (EB) in the treatments).

\begin{tabular}{lccr}
\hline & \multicolumn{3}{c}{ Digestibilidade aparente (\%) } \\
Tratamentos & MS & PB & EB \\
\hline Controle & $82,03^{\text {bc }}$ & $80,87^{\mathrm{a}}$ & $65,86^{\mathrm{b}}$ \\
Antibiótico & $85,22^{\mathrm{ab}}$ & $83,89^{\mathrm{a}}$ & $65,02^{\mathrm{b}}$ \\
TH1 $(0,02 \%)$ & $80,49^{\mathrm{c}}$ & $74,62^{\mathrm{b}}$ & $61,28^{\mathrm{c}}$ \\
TH2 $(0,04 \%)$ & $84,78^{\mathrm{ab}}$ & $80,70^{\mathrm{a}}$ & $70,84^{\mathrm{a}}$ \\
TH3 (0,06\%) & $86,62^{\mathrm{a}}$ & $82,73^{\mathrm{a}}$ & $66,52^{\mathrm{b}}$ \\
Média & 83,83 & 80,56 & 65,91 \\
CV (\%) & 2,546 & 3,649 & 2,969 \\
\hline
\end{tabular}

TH: Tecnaroma herbal; abMédias seguidas de letras diferentes na mesma coluna, dentro de cada variável, diferem entre si pelo Teste SNK $(p<0,05)$. 


\section{ÓLEOS ESSENCIAIS E DESEMPENHO DE LEITÕES RECÉM-DESMAMADOS}

experimento. Em um estudo com frangos estes autores observaram um aumento no CDMS, em relação ao tratamento controle, quando suplementou-se a dieta com dois tipos de extratos vegetais: um à base de orégano, canela e pimenta e o outro à base de sálvia, tomilho e alecrim. Entretanto, Utiyama et al.(2006), em experimento com leitões, utilizando um único tipo de extrato vegetal, observaram que o tratamento com antibiótico foi melhor em relação aos demais tratamentos, sendo que o tratamento com extrato vegetal apenas foi superior ao tratamento controle para o CDMS.

Com relação ao CDPB, os tratamentos não diferiram $(p>0,05)$ entre si, com exceção do tratamento TH1, que apresentou CDPB inferior aos demais tratamentos, enquanto para o CDEB, foi observado que o tratamento TH2 determinou o maior valor em relação aos outros quatro tratamentos.

O possível efeito antimicrobiano dos óleos essenciais pode explicar a melhora nos coeficientes de digestibilidade da matéria seca e da proteína bruta uma vez que, a redução da população microbiana além de disponibilizar mais carboidratos e aminoácidos para absorção, também reduz a adesão de bactérias e a produção de toxinas pelas mesmas, melhorando a integridade do epitélio intestinal (Butolo, 1999; Baynes e Varley, 2001).

Outra forma de se explicar a melhora verificada na digestibilidade dos nutrientes, proporcionadas, no geral, pelos tratamentos

\section{BIBLIOGRAFIA}

Andrigueto, J.M. (Ed.). 1986. Nutrição animal. 4ª ed. Nobel. São Paulo. v. 1.

Baynes, P. and Varley, M. 2001. Guthealth: practical considerations. In: Varley, M.A., Wiseman, J. (Ed.). The weaner pig: nutrition and management. CABI Publishing. Nothingham. Cap. 12. pp. 249257.

Brugalli, I. 2003. Alimentação alternativa: a utilização de fitoterápicos ou nutracêuticos como moduladores da imunidade e desempenho ani- com os óleos essenciais, é o fato que os extratos vegetais e óleos essenciais podem aumentar a secreção de saliva, suco gástrico, suco pancreático, sais biliares e enzimas do intestino delgado em ratos (Wang e Bourne, 1998). Esses dois compostos, quando presentes em uma dieta, proporcionam um aumento na produção de pepsina e ácido gástrico pelo organismo, contribuindo para uma redução do $\mathrm{pH}$ estomacal e do intestino delgado, estimulando a secreção pancreática (Mellor, 2000).

\section{CONCLUSÕES}

Os resultados encontrados nesta pesquisa sugerem que o produto $\mathrm{TH}$ pode, com grandes chances de sucesso, ser utilizado como aditivo alternativo aos agentes antimicrobianos como promotores do crescimento de leitões, uma vez que os tratamentos contendo os níveis de inclusão de $0,04 \%$ e $0,06 \%$ melhoraram o consumo de ração diário, o ganho de peso diário e a conversão alimentar dos animais em todos os períodos avaliados, bem como proporcionaram melhora na digestibilidade dos nutrientes.

Em virtude das variações nas respostas encontradas nesta pesquisa e na literatura, são necessários mais estudos para comprovar a eficácia dos óleos essenciais e determinar a melhor relação entre seus diferentes tipos e suas concentrações na dieta para maximizar o desempenho dos animais.

mal. Simpósio sobre Manejo e Nutrição de Aves e Suínos. Anais... Colégio Brasileiro de Nutrição Animal. Campinas. pp. 167-182.

Butolo, J.E. 1999. Uso de aditivos na alimentação de aves: frangos de corte. Simpósio sobre as Implicações Sócio-Econômicas do Uso de Aditivos na Produção Animal. Anais... CBNA. Campinas, SP. pp. 85-94.

Costa, L.B., Tse, M.L.P. e Miyada, V.S. 2007. Extratos vegetais como alternativas aos 


\section{BRANCO, SOARES, VIEITES, CABRAL E TAVARES}

antimicrobianos promotores de crescimento para leitões recém-desmamados. Rev. Bras. Zootecn., 36: 589-595.

Farag, R.S., Daw, Z.Y., Hewedi, F.M. and ElBaroty, G.S.A. 1989. Antimicrobial activity of some Egyptian spice essential oils. J. Food Protect., 52: 665-667.

Fialho, E.T., Bellaver, C., Gomes, P.C. e Albino, L.F.T. 1982. Composição química e valores de digestibilidade de alimentos, para suínos de pesos diferentes. Rev. Soc. Bras. Zoot., 11: 262-280.

Hernandez, F., Madrid, J., Garcia, V., Orengo, J. and Megias, M.D. 2004. Influence of two plant extracts on broilers performance, digestibility, and digestive organ size. Poultry Sci., 83: 169174.

Jones, G.P. 2001. High-performing livestock and consumer protection are not contradictory. Feed Magaz., 12: 12-19.

Kalemba, D. and Kunicka, A. 2003. Antibacterial and antifungal properties of essential oils. Current Med. Chem., 10: 813-829.

Kamel, C. 2000. A novel look at a classic approach of plant extracts. Feed Mix, 8: 19-21.

Lima, G.J.M.M., Viola, E.S., Nones, K. e Andreoli, P.R. 1999. Avaliação de dietas com BMD (bacitracina metileno disalicilato) e salinomicina sobre o desempenho de suínos em crescimento e terminação. Congresso Brasileiro de Veterinários Especialistas em Suínos, 9. Anais... ABRAVES. Belo Horizonte. pp. 464-465.

Mellor, S. 2000. Herbs and spices promote health and growth. Pig Progr., 16: 18-21.

Menten, J.F.M. 2001. Aditivos alternativos na produção de aves: probióticos e prebióticos. Reunião Anual da Sociedade Brasileira de Zootecnia, 38. Anais... Sociedade Brasileira de Zootecnia. Piracicaba. pp. 141-157.

Menten, J.F.M. 2002. Probióticos, prébióticos e aditivos fitogênicos na nutrição de aves.
Simpósio sobre Ingredientes na Alimentação Animal. Anais... Colégio Brasileiro de Nutrição Animal. Campinas. pp. 251-276.

Silva, E.N. 2000. Antibióticos intestinais naturais: bacteriocinas. Simpósio sobre Aditivos Alternativos na Nutrição Animal. Anais... Colégio Brasileiro de Nutrição Animal. Campinas. pp. 1524.

Miltemberg, G. 2000. Extratos herbais como substitutos de antimicrobianos na alimentação animal. Simpósio sobre Aditivos Alternativos na Nutrição Animal. Anais... IAC. Campinas. pp. 87100.

Oetting, L.L., Utiyama, C.E., Giani, P.A., Ruiz, U.S. e Miyada, V.S. 2006. Efeitos de extratos vegetais e antimicrobianos sobre a digestibilidade aparente, o desempenho, a morfometria dos órgãos e a histologia intestinal de leitões recémdesmamados. Rev. Bras. Zootecn., 35: 13891397.

Rostagno, H.S. 2005. Composição de alimentos e exigências nutricionais de aves e suínos (Tabelas brasileiras). $1^{a}$ impressão. Ed. Imp. Universidade da UFV. Viçosa.

Utiyama, C.E., Oetting, L.L., Giani, P.A., Ruiz, U.S. e Miyada, V.S. 2006. Efeitos de antimicrobianos, prebióticos, probióticos e extratos vegetais sobre a microbiota intestinal, a freqüência de diarréia e o desempenho de leitões recémdesmamados. Rev. Bras. Zootecn., 35: 23592367.

Wang, R., Li, D. and Bourne, S. 1998. Can 2000 years of herbal medicine history help us solve problems in year 2000? In: Alltech's Annual Symposium, 14. Proceedings... Alltech. Nottingham. pp. 168-184.

Zuanon, J.A.S., Fonseca, J.B., Rostagno, H.S., Almeida, E. e Silva, M. 1998. Efeito de promotores de crescimento sobre o desempenho de frangos de corte. Rev. Bras. Zootecn., 27: 9991005.

Archivos de zootecnia vol. 60, núm. 231, p. 706. 